\title{
Autocrine MCP-1/CCR2 signaling stimulates proliferation and migration of renal carcinoma cells
}

\author{
CHRISTOPH KÜPER ${ }^{1}$, FRANZ-XAVER BECK ${ }^{1}$ and WOLFGANG NEUHOFER ${ }^{2}$ \\ ${ }^{1}$ Department of Physiology, University of Munich, D-80336 Munich; \\ ${ }^{2}$ Division of Nephrology and Rheumatology, Clinical Center Traunstein, D-83278 Traunstein, Germany
}

Received July 30, 2015; Accepted May 13, 2016

DOI: $10.3892 / \mathrm{ol} .2016 .4875$

\begin{abstract}
The chemokine monocyte chemoattractant protein-1 [MCP-1; also known as chemokine (C-C motif) ligand 2] is an important mediator of monocyte recruitment during inflammatory processes. Pathologically high expression levels of MCP-1 by tumor cells have been observed in a variety of cancer types. In the majority of cases, high MCP-1 expression is associated with a poor prognosis, as infiltration of the tumor with inflammatory monocytes promotes tumor progression and metastasis. MCP-1 is also expressed in renal cell carcinoma (RCC). In the present study, the function and the regulation of MCP-1 was investigated in two RCC cell lines, CaKi-1 and 786-O. In both cell lines, expression of MCP-1 was significantly enhanced compared with non-cancerous control cells. As expected, secretion of MCP-1 into the medium facilitated the recruitment of peripheral blood monocytes via the chemokine (C-C motif) receptor type 2 (CCR2). As expression of CCR2 was also detected in 786-O and $\mathrm{CaKi}-1$ cells, the effect of autocrine MCP-1/CCR2 signaling was evaluated in these cells. In proliferation assays, administration of an MCP-1 neutralizing antibody or of a CCR2 antagonist to CaKi-1 and 786-O cells significantly decreased cell growth; supplementation of the growth medium with recombinant human MCP-1 had no additional effect on proliferation. The migration ability of RCC cells was impaired by MCP-1 neutralization or pharmacological CCR2 inhibition, while it was stimulated by the addition of recombinant human MCP-1, compared with untreated control cells. Finally, substantial differences in the regulation of MCP-1 expression were observed between RCC cell lines. In CaKi-1 cells, expression of MCP-1 appears to be largely mediated by the transcription factor nuclear factor of activated $\mathrm{T}$ cells 5 , while in 786-O cells, deletion of the tumor suppressor gene Von-Hippel-Lindau appeared to be responsible
\end{abstract}

Correspondence to: $\mathrm{Dr}$ Christoph Küper, Department of Physiology, University of Munich, 12 Pettenkoferstrasse, D-80336 Munich, Germany

E-mail: christoph.kueper@1rz.uni-muenchen.de

Key words: monocyte chemoattractant protein-1, chemokine (C-C motif) receptor type 2, autocrine signaling, nuclear factor of activated $\mathrm{T}$ cells 5 , renal cell carcinoma, CaKi-1 cells, 786-O cells for MCP-1 upregulation, as suggested by previous studies. Taken together, the results of the current study indicate that expression of MCP-1 in RCC cells promotes tumor progression and metastasis not only by paracrine, but also by autocrine, MCP-1/CCR2 signaling events, enhancing cell proliferation and migration ability. Therefore, the present findings suggest the MCP-1/CCR2 axis is a potential target for future therapeutic strategies in the treatment of metastatic RCC.

\section{Introduction}

Renal cell carcinoma (RCC) originates from epithelial cells of the proximal tubule and is the most common type of kidney cancer worldwide (1). The incidence rates among males are 6.6 in the UK, 9.7 in Germany, and 10 in the USA (per $100,000)$; incidence rates vary substantially across different countries or regions, for example 2.8 in Korea and 15.3 in the Czech Republic. Rates among females are approximately half of those among males (1). Due to its high resistance to conventional radiation and chemotherapy, metastatic RCC has a very poor prognosis. Significant efforts have been made in the last two decades to identify the genetic basis of RCC. In the majority of cases of sporadic RCC, deletion or mutation of the tumor suppressor gene Von-Hippel-Lindau (VHL) has been detected (2). VHL catalyzes the degradation of hypoxia-inducible factor- $\alpha$ (HIF- $\alpha$ ) under normoxic conditions, and loss of VHL results in accumulation of HIF- $\alpha$ and downstream induction of vascular endothelial growth factor (VEGF), as well as other factors that contribute to tumorigenesis (3). Targeting VEGF signaling pathways has increased the therapeutic options in the treatment of metastatic RCC (4). However, continued research is necessary to gain a better insight into the biological basis of carcinogenesis and metastasis, and to identify potential targets for novel therapeutic strategies.

Cancer cells produce a variety of chemokines (5). Chemokine secretion recruits inflammatory and immune cells to the tumor site; in the majority of cases, this process is associated with tumor progression and metastasis, as infiltrating inflammatory and immune cells facilitate tumor cell proliferation, angiogenesis, repression of the adaptive immune response and degradation of the extracellular matrix (6). One of the most important chemokines in this process is monocyte chemoattractant protein-1 [MCP-1; also known as chemokine (C-C motif) ligand 2], a member of the $\mathrm{C}-\mathrm{C}$ chemokine 
superfamily, which regulates leukocyte recruitment primarily via the chemokine (C-C motif) receptor type 2 (CCR2) (7). In addition to the recruitment of inflammatory cells, MCP-1 also induces angiogenesis by chemoattraction of CCR2-expressing endothelial cells $(8,9)$. High expression levels of MCP-1 in tumor cells and leukocyte recruitment has been described in various cancer types, including mammary (10), ovarian (11), pancreatic (12) and prostate (13) cancer.

Several studies have also addressed the role of MCP-1/CCR2 signaling in RCC. In patients exhibiting RCC, enhanced MCP-1 expression in tumor cells, and infiltration of the tumors with tumor-associated macrophages and tumor-infiltrating lymphocytes has been observed $(14,15)$. In xenograft models of RCC, enhanced MCP-1 expression is associated with microvessel density and tumor size $(16,17)$.

In prostate carcinoma cells, in addition to paracrine signaling to recruit inflammatory or endothelial cells, autocrine MCP-1 signaling to promote cell proliferation and invasiveness has also been observed (18). Deletion of VHL stimulates MCP-1 expression, possibly via VEGF signaling $(16,17,19)$; however, the mechanism of regulation of MCP-1 expression in $\mathrm{VHL}^{+} /^{+} \mathrm{RCC}$ is largely unknown. Therefore, the present study examined the regulation and function of MCP-1 in the $\mathrm{VHL}^{+}{ }^{+}$RCC cell line, $\mathrm{CaKi}-1$, and the $\mathrm{VHL}^{-/} \mathrm{RCC}$ cell line, 786-O. Particular attention was paid to a possible role of osmosensitive transcription factor nuclear factor of activated T cells 5 (NFAT5; also known as tonicity enhancer binding protein or osmotic response element binding protein), which stimulates MCP-1 expression in kidney epithelial cells during inflammatory processes $(20,21)$. Our previous study reported that cellular NFAT5 activity is enhanced in CaKi-1 cells, a phenomenon associated with increased expression of the NFAT5 target gene, S100 calcium binding protein A4 (S100A4; also known as metastasin), resulting in an enhanced proliferation and migration ability of these cells (22).

The aim of the present study was to determine whether autocrine MCP-1 signaling has a role in RCC cells and whether there are differences in the regulation of MCP-1 expression between different RCC cell lines. The present study provides evidence that autocrine MCP1/CCR2 signaling stimulates proliferation and migration of RCC cells, and that NFAT5 mediates the expression of MCP-1 in the $\mathrm{VHL}^{+} /^{+}$cell line CaKi-1, but not in the VHL\% cell line 786-O.

\section{Materials and methods}

Materials. Rabbit polyclonal anti-NFAT5 antibody was purchased from Santa Cruz Biotechnology, Inc. (Santa Cruz, CA, USA; dilution, 1:1,000; catalog no., sc-13035); rabbit polyclonal anti- $\beta$-actin antibody was purchased from Sigma-Aldrich (Deisenhofen, Germany; dilution 1:5,000; catalog no., A2066); goat anti-rabbit polyclonal horseradish peroxidase-conjugated anti-rabbit IgG antibody was purchased from Cell Signaling Technology (Beverly, MA, USA; dilution, 1:5,000; catalog no., 7074). Human MCP-1 enzyme-linked immunosorbent assay (ELISA) kit (catalog no., 900-K31), MCP-1 neutralizing antibody and recombinant human (rh) MCP-1 were obtained from PeproTech (Hamburg, Germany). PVP-free polycarbonate track etched filters were obtained from GVS S.p.A. (Bologna, Italy). Accell SMARTpool siRNA for knockdown of NFAT5 and Accell non-targeting siRNA \#2 were obtained from Thermo Fisher Scientific, Inc. (Epsom, UK). The CCR2 inhibitor, RS504393, and ethidium bromide were obtained from Sigma-Aldrich. DNA ladder 'Mass Ruler' was purchased from Thermo Fisher Scientific, Inc. Agarose was obtained from Bioline (Luckenwalde, Germany) and cell culture plates were obtained from Greiner-Bio One $\mathrm{GmbH}$ (Frickenhausen, Germany).

Cell culture. HK-2 (CRL-2190) immortalized human proximal tubule cells, and CaKi-1 (HTB-46) and 786-O (CRL-1932) RCC cells, all purchased from American Type Culture Collection (Manassas, VA, USA), were cultured in Dulbecco's modified Eagle medium (DMEM; Thermo Fisher Scientific, Inc.) supplemented with $10 \%$ fetal bovine serum (Biochrom $\mathrm{GmbH}$, Berlin, Germany), $100 \mathrm{U} / \mathrm{ml}$ penicillin and $100 \mu \mathrm{g} / \mathrm{ml}$ streptomycin (Invitrogen; Thermo Fisher Scientific, Inc., Karlsruhe, Germany). Cells were grown at $37^{\circ} \mathrm{C}$ in a humidified atmosphere (95\% air; 5\% $\mathrm{CO}_{2}$ ). Human peripheral blood mononuclear cells (PBMCs) were freshly prepared from the heparinized blood samples of healthy donors using Leucosep tubes (Greiner Bio-One $\mathrm{GmbH}$ ), according to the manufacturer's instructions. Blood samples were obtained in accordance with German federal law.

\section{Reverse transcription-quantitative polymerase chain reaction} (RT-qPCR) analysis. For determination of MCP-1, CCR2, NFAT5 and $\beta$-actin mRNA expression levels, total RNA was isolated from CaKi-1, 786-O and $\mathrm{HK}-2$ cells using TriFastreagent (Peqlab Biotechnologie GmbH, Erlangen, Germany), according to the manufacturer's instructions. The concentration of RNA in each sample was determined spectrophotometrically at $260 \mathrm{~nm}$. Absence of RNA degradation was tested by denaturing agarose gel electrophoresis on a $1.5 \%$ agarose/formaldehyde gel, checking for clear sharp bands for $28 \mathrm{~S}$ and 18S rRNA, and absence of excessive smear. To avoid amplification of genomic DNA, intron-spanning primer pairs were designed for RT-qPCR analysis. The primers (Metabion International AG, Martinsried, Germany) used were as follows: Forward, 5'-AGTCTCTGC CGCCCTTCT-3' and reverse, 5'-GTGACTGGGGCATTGATT G-3' for MCP-1; forward, 5'-CTGTCCACATCTCGTTCTCGG TTTA-3' and reverse, 5'-CCCAAAGACCCACTCATTTGC AGC-3' for CCR2; forward, 5'-AATCGCCCAAGTCCCTCT AC-3' and reverse, 5'-GGTGGTAAAGGAGCTGCAAG-3' for NFAT5; and forward, 5'-CCAACCGCGAGAAGATGA-3' and reverse, 5'-CCAGAGGCGTACAGGGATAG-3' for $\beta$-actin. The efficiency of each primer pair was tested in initial experiments. Standard curves were generated using standards of 100, 10, 1 and $0.1 \mathrm{ng}$ total starting RNA. In experiments comparing relative mRNA levels by RT-qPCR, the RNA concentration of the samples was adjusted to $25 \mathrm{ng} / \mu \mathrm{l}$ and constant amounts of RNA (75 ng) were used in each experiment. To ensure that the expression of the reference gene ( $\beta$-actin) was stable among all three cell lines and all experimental conditions, $\mathrm{Cq}$ values of $\beta$-actin were compared and found no significant differences. Experiments were conducted on a CFX Connect Real Time PCR Detection System (Bio-Rad Laboratories, Hercules, CA, USA) using the SensiMix SYBR One-Step kit (Bioline; catalog no., BIO 98005), according to the manufacturers' instructions. The relative mRNA expression levels of each gene was calculated 
using the $2^{-\Delta \Delta \mathrm{Cq}}$ method (23), with $\beta$-actin as the housekeeping gene. $\mathrm{Cq}$ values were corrected for PCR efficiency according to the following formula: $\mathrm{Cq}_{\mathrm{E}}=\mathrm{Cq}^{*}[\log (\mathrm{E}) / \log (2)]$, where $\mathrm{E}$ is efficiency and $100 \%$ efficiency is 2 . Negative controls lacking reverse transcriptase enzyme or RNA template were used in the experiments to exclude that traces of genomic DNA or other DNA contaminations were amplified. Specificity of PCR product formation was confirmed by monitoring melting point analysis and by agarose gel electrophoresis. Each experiment was repeated six times.

MCP-1 concentration. CaKi-1, 786-O and HK-2 cells were grown in 96-well plates, as described. After reaching confluency, growth medium was replaced by serum-free DMEM and cells were incubated for a further $48 \mathrm{~h}$. The concentration of MCP-1 in the cell culture supernatant was determined using the specific ELISA kit, according to the manufacturers' instructions. To normalize for differences in cell number, cells from each well were collected after removal of the culture supernatant, the total DNA content/well was determined spectrophotometrically at an absorbance of $260 \mathrm{~nm}$, and MCP-1 concentration was normalized to DNA content.

Proliferation assays. For proliferation assays, CaKi-1 and 786-O cells were seeded in 96-well plates at a density of $5 \times 10^{3}$ cells/well and incubated for $24 \mathrm{~h}$ for cell attachment, as described. Thereafter, growth medium was removed and cells were grown for another 24-96 h in serum-free DMEM in the presence of rh MCP-1 (10 ng/ml), MCP-1 neutralizing antibody $(1 \mu \mathrm{g} / \mathrm{ml})$ or CCR2 antagonist RS504393 $(10 \mu \mathrm{M})$. Control cells were left untreated. Relative cell numbers in each well were determined using the 3-(4,5-dimethylthiazol-2-yl)-2,5-diphenyltetrazolium bromide (MTT) assay (24). Briefly, cells were incubated with MTT (final concentration, $0.5 \mathrm{mg} / \mathrm{ml}$ in serum-free DMEM) for $4 \mathrm{~h}$ at $37^{\circ} \mathrm{C}$. Thereafter, the medium was removed, formazan crystals were solubilized in $100 \mu \mathrm{l}$ acidified isopropanol and absorption was measured at $565 \mathrm{~nm}$ on an Infinite M200 Pro microplate reader (Tecan Deutschland GmbH, Crailsheim, Germany).

Migration assays. Migration of PBMCs towards the conditioned medium (CM) of RCC cells was analyzed in a modified Boyden chamber (25). To obtain CM, CaKi-1 and 786-O cells were grown to $100 \%$ confluency in 24 -well plates, as described. Subsequently, the growth medium was replaced by serum-free DMEM and cells were incubated for a further $48 \mathrm{~h}$. The cell culture CM was collected by pipetting and centrifuged at $12,000 \mathrm{x} \mathrm{g}$ for $5 \mathrm{mins}$ to remove unattached cells or cell debris; subsequently, the supernatant was collected. To adjust for differences in cell number, cells from each well were collected after removal of CM and total DNA content/well was determined spectrophotometrically (absorbance at $260 \mathrm{~nm}$ ). CM were then normalized for DNA content between samples by adding serum-free DMEM. The CM was added to the lower compartments of the Boyden chamber for experimental samples, while controls were filled with unconditioned serum-free DMEM. In some experiments, the CM was preincubated with an MCP-1 neutralizing antibody $(1 \mu \mathrm{g} / \mathrm{ml})$ for $1 \mathrm{~h}$ at room temperature. The lower compartments were separated from the upper compartments by a porous polycarbonate membrane (pore size, $5 \mu \mathrm{m}$ ). The upper compartments were each filled with $10^{5}$ freshly prepared PBMCs dissolved in serum-free DMEM. In some experiments, PBMCs were preincubated with CCR2 antagonist RS504393 (10 $\mu \mathrm{M})$ for $1 \mathrm{~h}$ at room temperature. The Boyden chamber was incubated for $4 \mathrm{~h}$ at $37^{\circ} \mathrm{C}$ and PBMCs that had migrated across the polycarbonate membrane into the lower compartment were counted using a hemocytometer under an inverted light microscope.

Cell migration of CaKi-1 and 786-O cells was analyzed using the in vitro scratch assay (26), also known as the wound healing assay. CaKi-1 and 786-O cells were grown to confluency, as described. Subsequently, the growth medium was removed and the cell monolayers were 'scratched' with a $200-\mu 1$ pipette tip. Cells were further incubated in serum-free DMEM in the presence of MCP-1 neutralizing antibody (1 $\mu \mathrm{g} / \mathrm{ml})$, CCR2 antagonist RS504393 (10 $\mu \mathrm{M})$ or rh MCP-1 $(10 \mathrm{ng} / \mathrm{ml})$; control cells were left untreated. Cell migration into the immediate vicinity of the scratch was monitored using an inverted microscope (IM35; Zeiss, Oberkochen, Germany) and by capturing images every $4 \mathrm{~h}$.

Knockdown of NFAT5. CaKi-1 or 786-O cells were grown to $\sim 80 \%$ confluency, trypsinized, washed in PBS and finally resuspended in $100 \mu \mathrm{l}$ modified HEPES-buffered saline electroporation buffer (0.5\% HEPES, $1 \%$ glucose, $0.5 \%$ Ficoll, $5 \mathrm{mM} \mathrm{NaCl}, 135 \mathrm{mM} \mathrm{KCl,} 2 \mathrm{mM} \mathrm{MgCl}_{2}, \mathrm{pH} 7.4$ ) containing $2 \mu \mathrm{M}$ Accell SMARTpool NFAT5 siRNA or Accell non-targeting siRNA \#2 (control). Electroporation was conducted with a Gene Pulser Xcell Electroporation System (Bio-Rad Laboratories) at $140 \mathrm{~V}$ and 1,000 $\mu \mathrm{F}$ (exponential decay pulse) in a 2-mm cuvette and the cells seeded immediately thereafter in 24-well plates. Cells were incubated for 5 days prior to western blot analysis. Knockdown efficiency was determined by densitometric analysis of western blots using ImageJ version 1.47 software (National Institutes of Health, Bethesda, MD, USA)

Immunoblot analysis. The cells were seeded in 24-well plates and washed three times with chilled PBS. The cells were collected by scraping and lysed by the addition of $50 \mu 1$ urea (8 M)/PBS, followed by three freeze/thaw cycles and finally centrifuged at $12,000 \mathrm{x}$ g for $5 \mathrm{~min}$ at $4^{\circ} \mathrm{C}$. Supernatants were used as whole-cell-protein lysates. Protein concentration in the lysates was measured by the Bradford method (27), using a commercially available assay (Bio-Rad Laboratories), according to the manufacturer's protocol. Aliquots $(5-30 \mu \mathrm{g}$ protein) were subjected to $10 \%$ SDS-PAGE (28) and blotted onto nitrocellulose membranes (GE Healthcare, Pittsburgh, PA, USA). Non-specific binding sites were blocked with $5 \%$ non-fat dry milk in phosphate-buffered saline (PBS) containing $0.1 \%$ Tween-20 (PBS-T) at room temperature for $1 \mathrm{~h}$. Samples were incubated with primary antibodies in PBS-T containing 5\% non-fat dry milk overnight at $4^{\circ} \mathrm{C}$. Subsequently, the blots were washed 3 times with PBS-T for 5 min each, and the membranes incubated with the appropriate secondary antibody at room temperature for $1 \mathrm{~h}$ in PBS-T containing 5\% non-fat dry milk. After washing with PBS-T 3 times for 5 min each, immunocomplexes were visualized by enhanced chemiluminescence (Pierce ECL Western Blotting Substrate; Thermo Fisher Scientific, Inc.). 
A

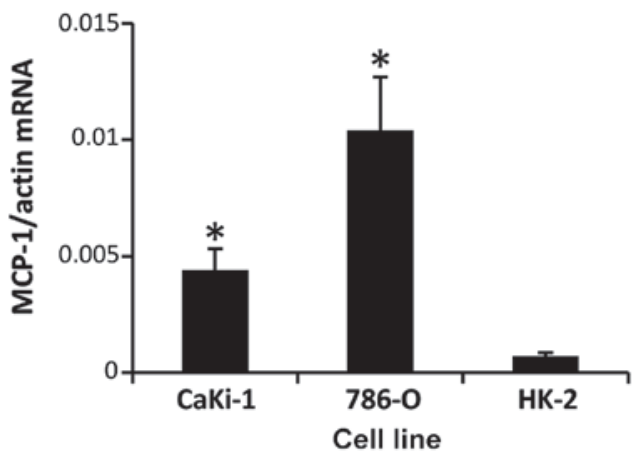

B

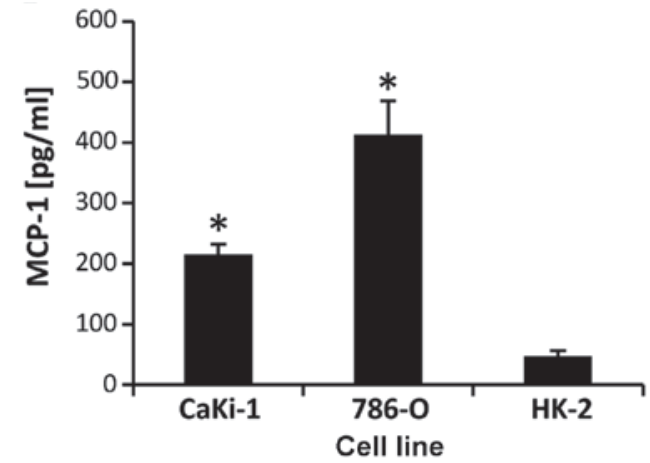

Figure 1. High expression of MCP-1 in renal cell carcinoma (RCC) cells (A) To determine MCP-1 transcription levels, RNA was extracted from 786-O and CaKi-1 RCC cells or non-cancerous proximal tubule HK-2 cells (control). The abundance of the MCP-1 mRNA transcript was determined by reverse transcription-quantitative polymerase chain reaction. Relative MCP-1 mRNA abundance was normalized to that of $\beta$-actin to correct for differences in RNA input. (B) To determine MCP-1 secretion levels, 786-O, CaKi-1 and HK-2 (control) cells were grown to confluency, then incubated for $48 \mathrm{~h}$ in serum-free Dulbecco's modified Eagle medium. Thereafter, medium samples were collected and the concentration of MCP-1 in the cell culture supernatant was determined by enzyme-linked immunosorbent assay. Data are presented as the mean \pm standard error of the mean $(n=6)$. ${ }^{*} \mathrm{P}<0.05$ vs. HK-2 control cells. MCP-1, monocyte chemoattractant protein-1.

Statistical analysis. Statistical analysis was performed using SPSS version 18.0 software (SPSS, Inc., Chicago, IL, USA). Data are expressed as means \pm standard error of the mean. The differences between the means were assessed by two-way analysis of variance followed by Tukey's post hoc test. $\mathrm{P}<0.05$ was used to indicate a statistically significant difference. All experiments were performed at least 3 times and representative results are shown.

\section{Results}

MCP-1 is highly expressed in RCC cells. CaKi-1 and 786-O cell lines were used as models for metastatic clear cell RCC. The proximal tubule cell line, HK-2, was used as non-cancerous control cells. Expression of MCP-1 was determined by RT-qPCR (Fig. 1A) and ELISA assay (Fig. 1B). The results showed that MCP-1 mRNA and protein is expressed in all three cell lines, however, $\mathrm{CaKi}-1$ and 786-O cells exhibited $\sim 5$-fold and $\sim 12$-fold increases in expression levels, respectively, compared with HK-2 cells, demonstrating that MCP-1 expression is enhanced in RCC cells.

MCP-1 secretion of RCC cells mediates monocyte recruitment. Secretion of MCP-1 by tumor cells and subsequent

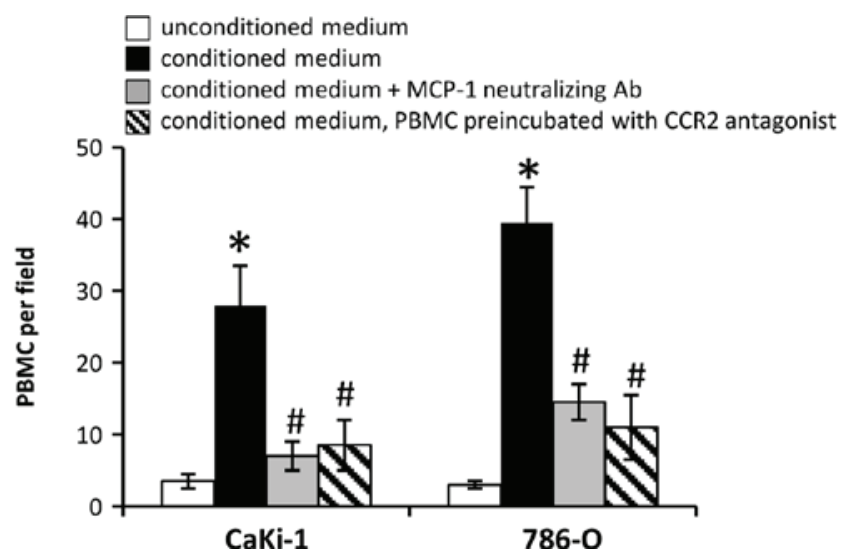

Figure 2. Paracrine monocyte chemoattractant protein-1/chemokine $(\mathrm{C}-\mathrm{C}$ motif) receptor type 2 signaling recruits $\mathrm{PBMCs}$ towards conditioned medium of renal cell carcinoma cells. Recruitment of PBMCs was analyzed in a modified Boyden chamber. The upper and lower compartments were separated by a porous $(5 \mu \mathrm{m})$ polycarbonate membrane filter. The lower compartments were filled with serum-free unconditioned medium ( $\square$; as control); conditioned medium ( $\mathbf{\square})$; or conditioned medium preincubated with an MCP-1 neutralizing antibody ( $₫$ ). The upper compartments were filled with $10^{5}$ PBMCs diluted in serum-free, unconditioned medium; in some experiments, PBMCs were preincubated with the CCR2 antagonist RS504393 (IN). The Boyden chamber was incubated for $4 \mathrm{~h}$. Thereafter, PBMCs that had migrated into the lower compartment were counted using a hemocytometer under a microscope. Data are presented as the mean \pm standard error of the mean $(n=6)$. ${ }^{*} \mathrm{P}<0.05$ vs. unconditioned control medium; ${ }^{\#} \mathrm{P}<0.05$ vs. conditioned medium. PBMCs, peripheral blood mononuclear cells.

recruitment of circulating blood monocytes has an important role during infiltration of the tumor stroma by inflammatory cells in various cancer types. The recruitment of PBMCs to conditioned, serum-free CM of CaKi-1 or 786-O cells was examined using a modified Boyden chamber. As expected, monocyte recruitment towards the $\mathrm{CM}$ of both cell lines was significantly stronger than towards unconditioned medium $(\mathrm{P}<0.05$; Fig. 2$)$. The results also demonstrate that the migration of monocytes towards the CM of 786-O cells, which express higher concentrations of MCP-1 than CaKi-1 cells (Fig. 1), was stronger than towards the CM of CaKi-1 cells $(\mathrm{P}<0.05$; Fig. 2). Furthermore, preincubation of the $\mathrm{CM}$ of both cell lines with an MCP-1 neutralizing antibody and preincubation of PBMCs with a CCR2 antagonist (RS504393) both significantly diminished monocyte recruitment compared with $\mathrm{CM}$ alone $(\mathrm{P}<0.05$; Fig. 2$)$. These data indicate that MCP-1 secreted by RCC cells attracts PBMCs via binding to CCR2.

Autocrine effects of $\mathrm{MCP}-1$ on the proliferation and migration of RCC cells. In prostate carcinoma cells, autocrine binding of MCP-1 to CCR2 stimulates their proliferation and migration ability (18). Expression of CCR2 in CaKi-1 and 786-O cells was detected by RT-qPCR in both cell lines. No significant differences in CCR2 expression levels were observed between the two cell lines $(\mathrm{P}>0.05$; Fig. 3A). The presence of CCR2 suggests that autocrine MCP-1/CCR2 signaling may also occur in RCC cells. To test this hypothesis, cells were grown in serum-free medium and treated with an MCP-1 neutralizing antibody, rh MCP-1 or a CCR2 antagonist (RS504393). Control cells were left untreated. Cell numbers were determined at 24-h intervals between 24 and 96 h by MTT assay. As shown 
A

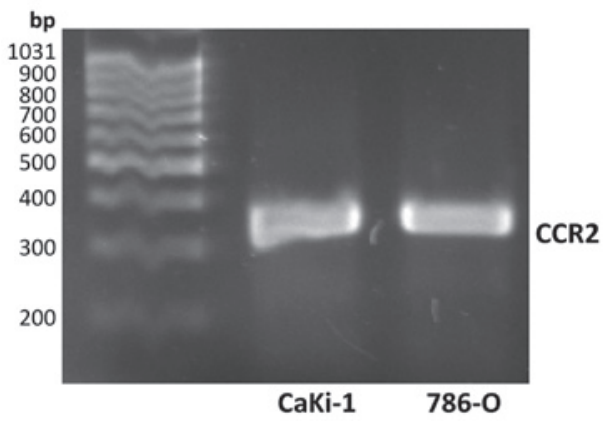

B





786-O

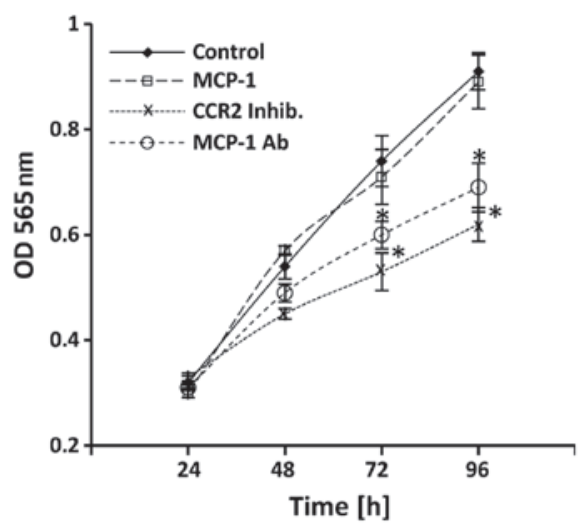

$+24 \mathrm{~h}$

C

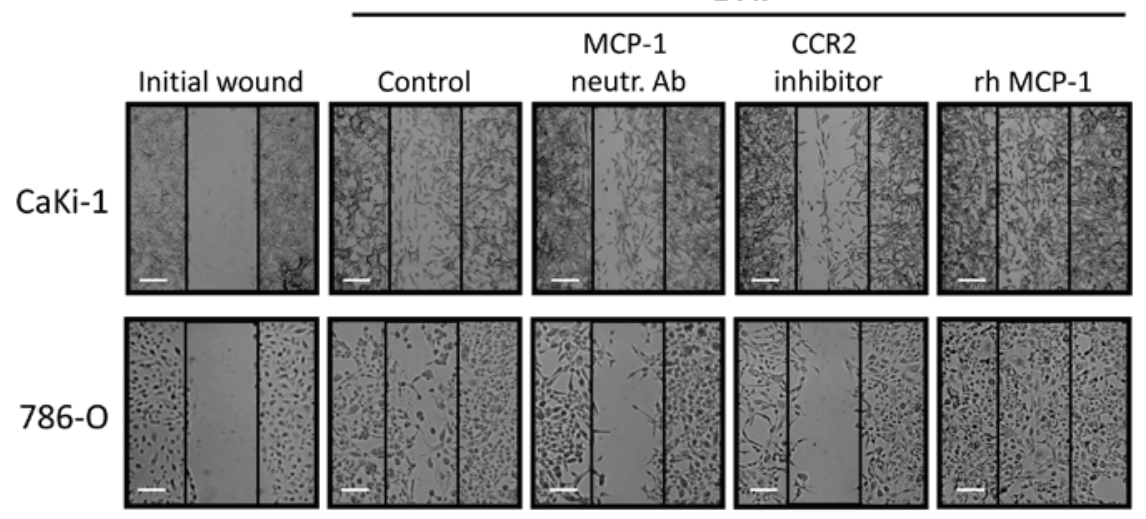

Figure 3. Autocrine MCP-1/CCR2 signaling stimulates the proliferation and migration of renal cell carcinoma cells. (A) RNA from 786-O and CaKi-1 cells was extracted and CCR2 expression was determined by reverse transcription-quantitative polymerase chain reaction. The correct size of the amplification product ( $324 \mathrm{bp}$ ) was verified by agarose gel electrophoresis. Relative CCR2 mRNA abundance was normalized to that of $\beta$-actin to correct for differences in RNA input. Data are presented as the mean \pm standard error of the mean (SEM; $\mathrm{n}=6$ ). (B) To determine proliferation, CaKi-1 or $786-\mathrm{O}$ cells $\left(5 \times 10^{3} /\right.$ well) were seeded into a 96 -well plate and incubated for $24 \mathrm{~h}$ for cell attachment. Thereafter, cells were grown for another 24-96 h in serum-free Dulbecco's modified Eagle medium and relative cell numbers in each well determined by MTT assay. Cells were grown in the presence of recombinant human (rh) MCP-1 ( $\square$ ), an MCP-1 neutralizing antibody (o) or the CCR2 antagonist RS504393 (x). The control cells were left untreated ( $)$. Data are presented as the mean \pm SEM $(\mathrm{n}=8) .{ }^{*} \mathrm{P}<0.05$ vs. untreated control. (C) To determine migration, confluent $\mathrm{CaKi}-1$ or $786-\mathrm{O}$ cells were scratched with a $200-\mu 1$ pipette tip and then incubated for another $24 \mathrm{~h}$. Cells were incubated in the presence of rh MCP-1, an MCP-1 neutralizing antibody or the CCR2 inhibitor RS504393. Control cells were left untreated. Shown are representative phase-contrast images of cells migrating into the wounded area, immediately after scratching and after $24 \mathrm{~h}$ incubation. Images were obtained at x40 magnification on a Zeiss IM35 inverted microscope. Scale bars, $100 \mu \mathrm{m}$. CCR2, chemokine (C-C motif) receptor type 2; OD, optical density; MCP-1, monocyte chemoattractant protein-1; inhib, inhibitor; Ab, antibody; rh, recombinant human.

in Fig. 3B, incubation with a CCR2 antagonist or neutralizing antibody significantly decreased the proliferation of 786-O and CaKi-1 cells compared with untreated control cells. However, additional supplementation of the growth medium with rh MCP-1 had no significant effect on cell growth compared with the control cells.

The migration ability of RCC cells was determined by performing a scratch assay. A monolayer of confluent CaKi-1 or 786-O cells was scratched with a pipette tip and cells were treated with MCP-1 neutralizing antibody, rh MCP-1 or CCR2 antagonist (RS504393). Control cells were left untreated. Cell migration into the immediate vicinity of the scratch was observed under a microscope. As indicated in Fig. 3C, migration of RCC cells into the wounded area in the presence of CCR2 antagonist or neutralizing MCP-1 antibody was markedly decreased compared with control cells after 24 h. By contrast, supplementation with recombinant MCP-1 enhanced cell migration ability. 
A



C



D

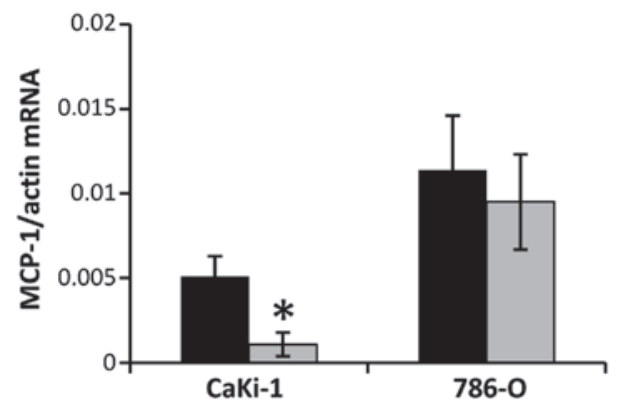

B



CaKi-1 786-O HK-2

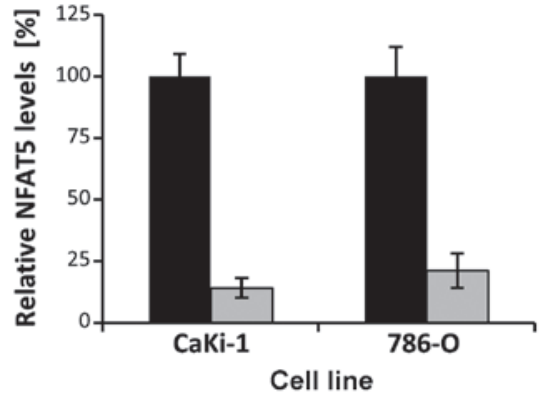

$\mathbf{E}$



Figure 4. NFAT5 knockdown attenuates MCP-1 expression in CaKi-1 but not in 786-O cells. (A) RNA from CaKi-1, 786-O and HK-2 cells was extracted, and the abundance of NFAT5 and $\beta$-actin mRNA transcripts determined by reverse transcription-quantitative polymerase chain reaction (RT-qPCR) . Relative mRNA abundance of NFAT5 was normalized to that of $\beta$-actin to correct for differences in RNA input. Data are presented as mean \pm standard error of the mean (SEM; n=6). P<0.05 vs. HK-2 control cells. (B) Protein lysates from CaKi-1, 786-O and HK-2 cells were processed for immunoblotting to determine the expression of NFAT5. To demonstrate comparable protein loading, the blots were also probed for $\beta$-actin. Representative blots from 4 independent experiments are shown. (C) CaKi-1 and 786-O cells were transfected with siRNA constructs specific for NFAT5 ( () ) or with non-targeting siRNA ( $\mathbf{m})$ as controls, and were grown for $72 \mathrm{~h}$. Thereafter, protein lysates were processed for immunoblotting to confirm NFAT5 knockdown. To demonstrate comparable protein loading, the blots were also probed for $\beta$-actin. Representative blots from 4 independent experiments are shown. Densitometric analysis of NFAT5 abundance was performed using ImageJ software. NFAT5 expression in CaKi-1 or 786-O cells transfected with non-targeting siRNA was defined as $100 \%$. Data are presented as the mean \pm SEM $(n=4)$. (D) CaKi-1 and 786-O cells were transfected with siRNA constructs specific for NFAT5 ( $\square$ ) or with non-targeting siRNA ( - as controls, and were grown for $72 \mathrm{~h}$. To determine MCP-1 transcription levels, RNA was extracted from the cells and the abundance of MCP-1 mRNA was determined by RT-qPCR. Relative MCP-1 mRNA abundance was normalized to that of $\beta$-actin to correct for differences in RNA input. Data are presented as the mean \pm SEM $(n=4)$. ${ }^{*} \mathrm{P}<0.05$ vs. CaKi-1 cells transfected with non-targeting control siRNA. (E) CaKi-1 and 786-O cells were transfected with siRNA constructs specific for NFAT5 ( $\square$ ) or with non-targeting siRNA ( $\bullet$ ) as controls, and were grown for $72 \mathrm{~h}$. To determine MCP-1 secretion, cells were subsequently incubated for $48 \mathrm{~h}$ in serum-free Dulbecco's modified Eagle medium. Thereafter, samples were collected and the concentration of MCP-1 in the cell culture supernatant was determined by enzyme-linked immunosorbent assay. Data are presented as the mean \pm SEM $(n=6)$. "P<0.05 vs. CaKi-1 transfected with non-targeting control siRNA. NFAT5, nuclear factor of activated T cells 5; MCP-1, monocyte chemoattractant protein-1.

These results indicate that autocrine $\mathrm{MCP}-1 / \mathrm{CCR} 2$ signaling stimulates the proliferation and migration of RCC cells. Endogenous MCP-1 expression levels appear to be sufficient for the maximum proliferation rate but not for the maximum migratory ability of RCC cells.

NFAT5 knockdown decreases MCP-1 expression in CaKi-1, but not in 786-O cells. MCP-1 expression in renal tubular cells is known to be regulated by the osmosensitive transcription factor NFAT5 $(20,21)$, which is highly expressed in CaKi-1 cells (22). To test the hypothesis that the high expression levels of MCP-1 in CaKi-1 cells are a result of high NFAT5 activity in RCC cells, NFAT5 mRNA and protein expression, and the effect of siRNA-mediated NFAT5 knockdown on MCP-1 expression were examined in $\mathrm{CaKi}-1$ and $786-\mathrm{O}$ cells. As shown in Fig. 4A and B, NFAT5 mRNA and protein expression, respectively, were significantly lower in 786-O cells than CaKi-1 cells $(\mathrm{P}<0.05)$, with their expression comparable to that in HK-2 cells. Transfection of CaKi-1 and 786-O cells with an NFAT5-specific siRNA construct resulted in a reduction of NFAT5 protein expression by 86 and $79 \%$, respectively, compared with cells transfected with non-specific control 
siRNA (P<0.05; Fig. 4C). Furthermore, NFAT5 knockdown significantly decreased the expression of MCP-1 in CaKi-1 cells $(\mathrm{P}<0.05)$, but had no significant impact on MCP-1 expression levels in 786-O cells (Fig. 4D and E). These results indicate that MCP-1 expression depends largely on NFAT5 in CaKi-1 cells, but not in 786-O cells.

\section{Discussion}

High expression levels of the chemokine MCP-1 have been observed in various types of tumor cell and MCP-1/CCR2 signaling is known to have an important role in tumor progression (29). To date, relatively few studies have addressed this signaling cascade in RCC. Yamasaki et al (17) used xenograft models to demonstrate that the expression of MCP-1 in RCC cells is correlated with tumor growth. The protumorigenic effects of MCP-1 are typically explained by the angiogenic activity and enhanced recruitment of inflammatory cells, which in turn secrete a variety of growth factors into the tumor microenvironment. The present study provides evidence that, in addition to this paracrine MCP-1 signaling, autocrine MCP-1 signaling also occurs in RCC cells, and may contribute to tumor progression by promoting cell proliferation and cell migration. In the current study, the expression of MCP-1 and its receptor, CCR2, were detected in 786-O and $\mathrm{CaKi}-1$ RCC cells. Neutralization of MCP-1 by a specific antibody or pharmacological inhibition of CCR2 significantly decreased cell growth in both cell lines. The results of the current study agree with a previous study, in which prostate carcinoma cell proliferation was stimulated by autocrine MCP-1/CCR2 signaling $(18,30)$. Therefore, another important mechanism for the development of metastatic RCC may be the positive effect of autocrine MCP-1/CCR2 signaling on the cell migration ability of CaKi-1 and 786-O cells.

The results of the present study also indicate that endogenous MCP-1 expression levels are sufficient for maximum proliferation, but not for maximum migration of RCC cells. These limitations regarding migration ability may be overcome during metastasis by an increase in MCP-1 expression (31). Metastatic RCC is characterized by frequent bone metastases (32). During metastasis, osteoblast-derived factors increase MCP-1 expression in RCC cells to enhance cancer cell migration via an autocrine mechanism, thereby facilitating bone metastasis (31). This process is mediated via the cancer-associated cell membrane glycoprotein, dysadherin. Data from the literature suggest that a similar mechanism occurs during bone metastasis of mammary carcinoma cells (33), indicating that autocrine MCP-1/CCR2 signaling may also have an important role during bone metastasis in other types of cancer.

The importance of autocrine MCP-1/CCR2 signaling, particularly during metastasis of RCC cells, is also highlighted by the fact that only $15 \%$ of primary tumor cells but $52 \%$ of metastatic cells express CCR2 (34). These data suggest that CCR2 may be a potential target for future treatment strategies of metastatic RCC (and other cancer types), as pharmacological inhibition of CCR2 may not only influence paracrine MCP-1 signaling to decrease the recruitment of inflammatory monocytes and endothelial cells, but also affect autocrine MCP-1 signaling, thereby decreasing the proliferation and migration ability of carcinoma cells. The first clinical trials investigating the therapeutic potential of pharmacological CCR2 inhibitors in pancreatic cancer are currently in progress (35).

For future studies, it will be important to evaluate the proliferative and pro-migratory pathways that are activated by autocrine MCP-1/CCR2 signaling in cancer cells. It is well documented that CCR2 activates the phosphatidyl inositol 3 kinase (PI3K)/Akt pathway (30), which in turn can stimulate cell proliferation, for example via activation of the mammalian target of rapamycin signaling pathway (36). CCR2 can also stimulate cell migration, for example via activation of p70S6 kinase (37). However, due to the complexity of the PI3K/Akt signaling pathway, extensive analysis of downstream signaling molecules will be necessary to reveal the detailed molecular mechanisms of autocrine MCP-1/CCR2 signaling in cancer cells.

The results of the present and previous studies indicate that there are substantial differences in the regulation of MCP-1 expression between $\mathrm{VHL}^{-}$- RCC cell lines, such as 786-O, and $\mathrm{VHL}^{+} /^{+}$cells, such as CaKi-1 $(16,17,19)$, and this may have an impact on the progression and treatment of RCC. Our previous study showed that, in CaKi-1 cells, NFAT5 activity is increased (22) and MCP-1 expression largely depends on this increased NFAT5 activity, as supported by the results of the present study. By contrast, NFAT5 is not increased in 786-O cells compared with non-cancerous HK-2 cells, and MCP-1 expression is appears to be mediated by VEGF signaling in 786-O cells and other VHL $\%$ RCC cell lines (19). The expression of MCP-1 is generally higher in $\mathrm{VHL} /$ cells than in $\mathrm{VHL}^{+}+$ cells (17). Accordingly, enhanced MCP-1 expression is associated with increased angiogenesis and tumor growth in 786-O murine xenografts compared with $\mathrm{CaKi}-1$ xenografts. Treatment of this 786-O murine xenograft with the VEGF-targeting monoclonal antibody, bevacizumab, significantly decreased angiogenesis and tumor growth, while $\mathrm{CaKi}-1$ xenografts were virtually unaffected by this therapy (17). Therefore, drugs that target the VEGF signaling pathway and are already approved for the treatment of metastatic RCC, such as bevacizumab, sunitinib or sorafenib, may elicit their anti-tumorigenic effects in part by decreasing MCP-1 expression in $\mathrm{VHL}^{-1} \mathrm{RCC}$, but may not affect auto- and paracrine $\mathrm{MCP}-1 / \mathrm{CCR} 2$ signaling in $\mathrm{VHL}^{+/+} \mathrm{RCC}$.

NFAT5 is another potential target for future treatment strategies of $\mathrm{VHL}^{+} /^{+} \mathrm{RCC}$ and other tumor entities. Under physiological conditions, NFAT5 regulates the expression of several osmoprotective and urinary concentrating genes in the renal medulla (38-42), as well as the expression of pro-inflammatory cytokines in macrophages and lymphocytes $(43,44)$. Several studies suggest that NFAT5 has an important role in the development of various cancer types, such as non-small cell lung cancer $(45,46)$, melanoma $(47)$, leiomyoma (48), breast cancer (49-51) and colon carcinoma (52-54). A recent study identified NFAT5 as a master regulator of inflammatory breast cancer (55), which is the most aggressive type of breast cancer due to its high angiogenic potential, invasiveness, and frequent local and metastatic recurrences. An important target gene of NFAT5 in the context of tumor progression is S100A4, as demonstrated in colon, breast and RCC cells $(22,51,52,56)$. The present study provides evidence that, in addition to S100A4, MCP-1 may also be upregulated 
by NFAT5 in carcinoma cells. The upregulation of MCP-1 by dysadherin has an important role during bone metastasis of cancer cells; however, the molecular mechanisms by which dysadherin enhances MCP-1 expression are largely unknown. Notably, dysadherin is a modulator of $\mathrm{Na}^{+} / \mathrm{K}^{+}$-ATPase $(57,58)$, which has been shown to stimulate NFAT5 activity (59-61). As NFAT5 and nuclear factor- $\kappa \mathrm{B}(\mathrm{NF}-\kappa \mathrm{B})$, which is also activated by dysadherin (33), can cooperatively induce MCP-1 expression $(21,62)$, we propose that dysadherin stimulates MCP-1 expression via co-activation of NFAT5 and NF- $\mathrm{BB}$. However, the details of this mechanism remain to be elucidated.

In conclusion, the present study demonstrated that autocrine $\mathrm{MCP}-1 / \mathrm{CCR} 2$ signaling stimulates the proliferation and migration ability of RCC cells. MCP-1 expression in the $\mathrm{VHL}^{+} /^{+}$cell line, CaKi-1, but not in the $\mathrm{VHL}^{-}$cell line, 786-O, is mediated by the transcription factor NFAT5, further emphasizing the role of NFAT5 as a protumorigenic factor. The present results suggest that MCP-1/CCR2 axis and/or NFAT5 may act as potential targets for future therapeutic strategies in the treatment of metastatic RCC.

\section{Acknowledgements}

The present study was supported by grants from the Deutsche Forschungsgemeinschaft (grant no., NE839/6-1), the Münchener Medizinische Wochenschrift and the Friedrich Baur Foundation (grant no., FBS05/11) (Munich, Germany). The authors thank Dr John Davis and Dr Christopher Batters for critical reading of the manuscript. The technical assistance of Mrs. Maria-Luisa Fraek is gratefully acknowledged.

\section{References}

1. Chow WH, Dong LM and Devesa SS: Epidemiology and risk factors for kidney cancer. Nat Rev Urol 7: 245-257, 2010.

2. Linehan WM, Walther MM and Zbar B: The genetic basis of cancer of the kidney. J Urol 170: 2163-2172, 2003.

3. Patel PH, Chadalavada RS, Chaganti RS and Motzer RJ: Targeting von Hippel-Lindau pathway in renal cell carcinoma. Clin Cancer Res 12: 7215-7220, 2006.

4. Motzer RJ: New perspectives on the treatment of metastatic renal cell carcinoma: An introduction and historical overview. Oncologist 16 (Suppl 2): S1-S3, 2011.

5. Balkwill F: Cancer and the chemokine network. Nat Rev Cancer 4: 540-550, 2004.

6. Solinas G, Germano G, Mantovani A and Allavena P: Tumor-associated macrophages (TAM) as major players of the cancer-related inflammation. J Leukoc Biol 86: 1065-1073, 2009

7. Deshmane SL, Kremlev S, Amini S and Sawaya BE: Monocyte chemoattractant protein-1 (MCP-1): An overview. J Interferon Cytokine Res 29: 313-326, 2009.

8. Salcedo R, Ponce ML, Young HA, Wasserman K, Ward JM, Kleinman HK, Oppenheim JJ and Murphy WJ: Human endothelial cells express CCR2 and respond to MCP-1: Direct role of MCP-1 in angiogenesis and tumor progression. Blood 96: 34-40, 2000.

9. Weber KS, Nelson PJ, Gröne HJ and Weber C: Expression of CCR2 by endothelial cells: Implications for MCP-1 mediated wound injury repair and in vivo inflammatory activation of endothelium. Arterioscler Thromb Vasc Biol 19: 2085-2093, 1999.

10. Ueno T, Toi M, Saji H, Muta M, Bando H, Kuroi K, Koike M, Inadera $\mathrm{H}$ and Matsushima $\mathrm{K}$ : Significance of macrophage chemoattractant protein-1 in macrophage recruitment, angiogenesis, and survival in human breast cancer. Clin Cancer Res 6: 3282-3289, 2000.

11. Negus RP, Stamp GW, Hadley J and Balkwill FR: Quantitative assessment of the leukocyte infiltrate in ovarian cancer and its relationship to the expression of $\mathrm{C}-\mathrm{C}$ chemokines. Am J Pathol 150: 1723-1734, 1997.
12. Sanford DE, Belt BA, Panni RZ, Mayer A, Deshpande AD, Carpenter D, Mitchem JB, Plambeck-Suess SM, Worley LA and Goetz BD: Inflammatory monocyte mobilization decreases patient survival in pancreatic cancer: A role for targeting the CCL2/CCR2 axis. Clin Cancer Res 19: 3404-3415, 2013.

13. Loberg RD, Ying C, Craig M, Yan L, Snyder LA and Pienta KJ: CCL2 as an important mediator of prostate cancer growth in vivo through the regulation of macrophage infiltration. Neoplasia 9: 556-562, 2007.

14. Daurkin I, Eruslanov E, Stoffs T, Perrin GQ, Algood C, Gilbert SM, Rosser CJ, Su LM, Vieweg J and Kusmartsev S: Tumor-associated macrophages mediate immunosuppression in the renal cancer microenvironment by activating the 15-lipoxygenase-2 pathway. Cancer Res 71: 6400-6409, 2011.

15. Ferrero E, Fabbri M, Poggi A, Galati G, Bernasconi S and Zocchi MR: Tumor-driven matrix invasion by infiltrating lymphocytes: Involvement of the alpha1 integrin I-domain. Eur J Immunol 28: 2530-2536, 1998.

16. Kanno T, Kamba T, Yamasaki T, Shibasaki N, Saito R, Terada N, Toda Y, Mikami Y, Inoue T, Kanematsu A, et al: JunB promotes cell invasion and angiogenesis in VHL-defective renal cell carcinoma. Oncogene 31: 3098-3110, 2012.

17. Yamasaki T, Kamba T, Kanno T, Inoue T, Shibasaki N, Arakaki R, Yamada T, Kondo K, Kamoto T, Nishiyama H, et al: Tumor microvasculature with endothelial fenestrations in VHL null clear cell renal cell carcinomas as a potent target of anti-angiogenic therapy. Cancer Sci 103: 2027-2037, 2012.

18. Lu Y, Cai Z, Galson DL, Xiao G, Liu Y, George DE, Melhem MF, Yao Z and Zhang J: Monocyte chemotactic protein-1 (MCP-1) acts as a paracrine and autocrine factor for prostate cancer growth and invasion. Prostate 66: 1311-1318, 2006.

19. Li C, Liu B, Dai Z and Tao Y: Knockdown of VEGF receptor-1 (VEGFR-1) impairs macrophage infiltration, angiogenesis and growth of clear cell renal cell carcinoma (CRCC). Cancer Biol Ther 12: 872-880, 2011.

20. Kojima R, Taniguchi H, Tsuzuki A, Nakamura K, Sakakura Y and Ito M: Hypertonicity-induced expression of monocyte chemoattractant protein-1 through a novel cis-acting element and MAPK signaling pathways. J Immunol 184: 5253-5262, 2010.

21. Roth I, Leroy V, Kwon HM, Martin PY, Féraille E and Hasler U: Osmoprotective transcription factor NFAT5/TonEBP modulates nuclear factor-kappaB activity. Mol Biol Cell 21: 3459-3474, 2010.

22. Küper C, Beck FX and Neuhofer W: NFAT5-mediated expression of S100A4 contributes to proliferation and migration of renal carcinoma cells. Front Physiol 5: 293, 2014.

23. Livak KJ and Schmittgen TD: Analysis of relative gene expression data using real-time quantitative PCR and the 2(-Delta Delta C(T)) Method. Methods 25: 402-408, 2001.

24. Mosmann T: Rapid colorimetric assay for cellular growth and survival: Application to proliferation and cytotoxicity assays. J Immunol Methods 65: 55-63, 1983.

25. Falk W, Goodwin RH Jr and Leonard EJ: A 48-well micro chemotaxis assembly for rapid and accurate measurement of leukocyte migration. J Immunol Methods 33: 239-247, 1980.

26. Liang CC, Park AY and Guan JL: In vitro scratch assay: A convenient and inexpensive method for analysis of cell migration in vitro. Nat Protoc 2: 329-333, 2007.

27. Bradford MM: A rapid and sensitive method for the quantitation of microgram quantities of protein utilizing the principle of protein-dye binding. Anal Biochem 72: 248-254, 1976.

28. Laemmli UK: Cleavage of structural proteins during the assembly of the head of bacteriophage T4. Nature 227: 680-685, 1970.

29. Conti I and Rollins BJ: CCL2 (monocyte chemoattractant protein-1) and cancer. Semin Cancer Biol 14: 149-154, 2004.

30. Loberg RD, Day LL, Harwood J, Ying C, St John LN, Giles R, Neeley CK and Pienta KJ: CCL2 is a potent regulator of prostate cancer cell migration and proliferation. Neoplasia 8: 578-586, 2006.

31. Schuler Y, Lee-Thedieck C, Geiger K, Kaiser T, Ino Y, Aicher WK and Klein G: Osteoblast-secreted factors enhance the expression of dysadherin and CCL2-dependent migration of renal carcinoma cells. Int J Cancer 130: 288-299, 2012.

32. Coleman RE: Clinical features of metastatic bone disease and risk of skeletal morbidity. Clin Cancer Res 12 (Suppl): S6243-S6249, 2006

33. Nam JS, Kang MJ, Suchar AM, Shimamura T, Kohn EA, Michalowska AM, Jordan VC, Hirohashi S and Wakefield LM: Chemokine (C-C motif) ligand 2 mediates the prometastatic effect of dysadherin in human breast cancer cells. Cancer Res 66: 7176-7184, 2006 
34. Wyler L, Napoli CU, Ingold B, Sulser T, Heikenwälder M, Schraml $\mathrm{P}$ and Moch $\mathrm{H}$ : Brain metastasis in renal cancer patients: Metastatic pattern, tumour-associated macrophages and chemokine/chemoreceptor expression. Br J Cancer 110: 686-694, 2014.

35. Wang-Gillam A, Nywening TM, Sanford DE, Lockhart AC, Suresh R, Tan BR, Lim KH, Sorscher S, Fowler K, Amin MA, et al: Phase IB study of FOLFIRINOX plus PF-04136309 in patients with borderline resectable and locally advanced pancreatic adenocarcinoma (PC). J Clin Oncol 33 (Suppl; Abstract 388): 2015.

36. Vivanco I and Sawyers CL: The phosphatidylinositol 3-Kinase AKT pathway in human cancer. Nat Rev Cancer 2: 489-501, 2002

37. Qian Y, Corum L, Meng Q, Blenis J, Zheng JZ, Shi X, Flynn DC and Jiang BH: PI3K induced actin filament remodeling through Akt and p70S6K1: Implication of essential role in cell migration. Am J Physiol Cell Physiol 286: C153-C163, 2004.

38. Miyakawa H, Woo SK, Chen CP, Dahl SC, Handler JS and Kwon HM: Cis- and trans-acting factors regulating transcription of the BGT1 gene in response to hypertonicity. Am J Physiol 274 F753-F761, 1998.

39. Miyakawa H, Woo SK, Dahl SC, Handler JS and Kwon HM: Tonicity-responsive enhancer binding protein, a rel-like protein that stimulates transcription in response to hypertonicity. Proc Natl Acad Sci USA 96: 2538-2542, 1999.

40. Zhang Z,Ferraris JD, Brooks HL, Brisc I and Burg MB: Expression of osmotic stress-related genes in tissues of normal and hyposmotic rats. Am J Physiol Renal Physiol 285: F688-F693, 2003.

41. Woo SK, Lee SD, Na KY, Park WK and Kwon HM: TonEBP/NFAT5 stimulates transcription of HSP70 in response to hypertonicity. Mol Cell Biol 22: 5753-5760, 2002.

42. Han KH, Woo SK, Kim WY, Park SH, Cha JH, Kim J and Kwon HM: Maturation of TonEBP expression in developing rat kidney. Am J Physiol Renal Physiol 287: F878-F885, 2004.

43. López-Rodriguez C, Aramburu J, Jin L, Rakeman AS, Michino M and Rao A: Bridging the NFAT and NF-kappaB families: NFAT5 dimerization regulates cytokine gene transcription in response to osmotic stress. Immunity 15: 47-58, 2001.

44. Esensten JH, Tsytsykova AV, Lopez-Rodriguez C, Ligeiro FA Rao A and Goldfeld AE: NFAT5 binds to the TNF promoter distinctly from NFATp, c, 3 and 4 , and activates TNF transcription during hypertonic stress alone. Nucleic Acids Res 33: 3845-3854, 2005.

45. Zhong L, Peng X, Hidalgo GE, Doherty DE, Stromberg AJ and Hirschowitz EA: Identification of circulating antibodies to tumor-associated proteins for combined use as markers of non-small cell lung cancer. Proteomics 4: 1216-1225, 2004.

46. Mijatovic T, Mathieu V, Gaussin JF, De Nève N, Ribaucour F, Van Quaquebeke E, Dumont P, Darro F and Kiss R: Cardenolide-induced lysosomal membrane permeabilization demonstrates therapeutic benefits in experimental human non-small cell lung cancers. Neoplasia 8: 402-412, 2006.

47. Levy C, Khaled M, Iliopoulos D, Janas MM, Schubert S, Pinner S, Chen PH, Li S, Fletcher AL, Yokoyama S, et al: Intronic miR-211 assumes the tumor suppressive function of its host gene in melanoma. Mol Cell 40: 841-849, 2010.

48. McCarthy-Keith DM, Malik M, Britten J, Segars J and Catherino WH: Gonadotropin-releasing hormone agonist increases expression of osmotic response genes in leiomyoma cells. Fertil Steril 95: 2383-2387, 2011.
49. Germann S, Gratadou L, Zonta E, Dardenne E, Gaudineau B, Fougère M, Samaan S, Dutertre M, Jauliac S and Auboeuf D: Dual role of the ddx $5 / d d x 17$ RNA helicases in the control of the pro-migratory NFAT5 transcription factor. Oncogene 31: 4536-4549, 2012.

50. Jauliac S, López-Rodriguez C, Shaw LM, Brown LF, Rao A and Toker A: The role of NFAT transcription factors in integrin-mediated carcinoma invasion. Nat Cell Biol 4: 540-544, 2002.

51. Chen M, Sinha M, Luxon BA, Bresnick AR and O'Connor KL: Integrin alpha6beta4 controls the expression of genes associated with cell motility, invasion, and metastasis, including S100A4/metastasin. J Biol Chem 284: 1484-1494, 2009.

52. Chen M, Sastry SK and O'Connor KL: Src kinase pathway is involved in NFAT5-mediated S100A4 induction by hyperosmotic stress in colon cancer cells. Am J Physiol Cell Physiol 300: C1155-C1163, 2011.

53. Alvarez-Diaz S, Valle N, Ferrer-Mayorga G, Lombardía L, Herrera M, Domínguez O, Segura MF, Bonilla F, Hernando E and Muñoz A: MicroRNA-22 is induced by vitamin D and contributes to its antiproliferative, antimigratory and gene regulatory effects in colon cancer cells. Hum Mol Genet 21: 2157-2165, 2012.

54. Slattery ML, Lundgreen A, Bondurant KL and Wolff RK: Tumor necrosis factor-related genes and colon and rectal cancer. Int J Mol Epidemiol Genet 2: 328-338, 2011.

55. Remo A, Simeone I, Pancione M, Parcesepe P, Finetti P, Cerulo L, Bensmail H, Birnbaum D, Van Laere SJ, Colantuoni V, et al: Systems biology analysis reveals NFAT5 as a novel biomarker and master regulator of inflammatory breast cancer. J Transl Med 13: 138, 2015.

56. Li JT, Wang LF, Zhao YL, Yang T, Li W, Zhao J, Yu F, Wang L, Meng YL, Liu NN, et al: Nuclear factor of activated T cells 5 maintained by Hotair suppression of miR-568 upregulates S100 calcium binding protein A4 to promote breast cancer metastasis. Breast Cancer Res 16: 454, 2014

57. Lubarski I, Asher C and Garty H: FXYD5 (dysadherin) regulates the paracellular permeability in cultured kidney collecting duct cells. Am J Physiol Renal Physiol 301: F1270-F1280, 2011

58. Lubarski I, Pihakaski-Maunsbach K, Karlish SJ, Maunsbach AB and Garty $\mathrm{H}$ : Interaction with the $\mathrm{Na}, \mathrm{K}$-ATPase and tissue distribution of FXYD5 (related to ion channel). J Biol Chem 280: 37717-37724, 2005.

59. Lim SW, Ahn KO, Sheen MR, Jeon US, Kim J, Yang CW and Kwon HM: Downregulation of renal sodium transporters and tonicity-responsive enhancer binding protein by long-term treatment with cyclosporin A. J Am Soc Nephrol 18: 421-429, 2007.

60. Jeon US, Han KH, Park SH, Lee SD, Sheen MR, Jung JY, Kim WY, Sands JM, Kim J and Kwon HM: Downregulation of renal TonEBP in hypokalemic rats. Am J Physiol Renal Physiol 293: F408-F415, 2007.

61. Neuhofer W, Woo SK, Na KY, Grunbein R, Park WK, Nahm O, Beck FX and Kwon HM: Regulation of TonEBP transcriptional activator in MDCK cells following changes in ambient tonicity. Am J Physiol Cell Physiol 283: C1604-C1611, 2002.

62. Küper C, Beck FX and Neuhofer W: NFAT5 contributes to osmolality-induced MCP-1 expression in mesothelial cells. Mediators Inflamm 2012: 513015, 2012. 